Aiming high, aiming low, not knowing where to go: Career aspirations and later outcomes of young people with special educational needs

\author{
Leslie Morrison Gutman \\ University College London \\ Ingrid Schoon \\ UCL Institute of Education \\ WZB - Berlin Social Science Centre
}

Gutman, L.M. \& Schoon (2017). Aiming high, aiming low, not knowing where to go: Career aspirations and later outcomes of adolescents with special educational needs. International Journal of Educational Research.

Labelling

Correspondence concerning this article should be addressed to Leslie Morrison Gutman:

l.gutman@ucl.ac.uk 


\begin{abstract}
This study investigates the role of early career aspirations in predicting the later educational and occupational outcomes of adolescents designated as having special educational needs (SEN) in comparison to those without SEN. Drawing upon the Longitudinal Study of Young People in England, the sample includes adolescents with and without SEN who attended mainstream schools $(n=9,966)$. Findings showed that high career aspirations at age 14 were more predictive of later educational and employment outcomes from ages 16 to 20 for adolescents with SEN compared to those without SEN. Findings underline the importance of helping adolescents with SEN identify their career aspirations in early adolescence and adopt appropriate strategies to encourage them to reach their potential.
\end{abstract}




\section{Aiming high, aiming low, not knowing where to go: Career aspirations and later outcomes of adolescents with special educational needs}

Previous research has shown that many adolescents with high career aspirations obtain higher educational qualifications as well as jobs with higher occupational prestige and wage attainments later in adulthood compared to those with low aspirations (Mello, 2008; Schoon, Martin, \& Ross, 2007; Schoon \& Parsons, 2002; Schoon \& Polek, 2011). However, the association between early occupational aspirations and attainment is not necessarily a straightforward one (Carter-Wall \& Whitfield, 2012; Gutman \& Akerman, 2008). While most adolescents have aspirations to attend university and get a good job (Schoon, 2010), the barrier for many is not having low aspirations - but realizing their ambitions (Schneider and Stevenson, 1999).

The relationship between career aspirations and later attainment may be especially complicated for adolescents with special educational needs (SEN). While the identification of SEN is intended to provide additional support for the student, it also results in labelling with the risks of negative stigma, feelings of inferiority and reduced expectations from teachers and parents (Cambell, Gilmore, \& Cuskelly, 2003; Cross \& Donovan, 2002; Norwich, 1992). Studies have shown that adolescents with learning difficulties not only have lower career aspirations (Rojewski, 1996, 1999), they also experience significantly worse educational and employment outcomes compared to their peers without learning difficulties (Rojewski, Lee, \& Gregg, 2014; Sanford et al., 2011).

In order to support young people with SEN, we need to have better understanding of the relationship between their career aspirations and later educational and employment outcomes, especially in comparison to those without SEN. While adolescents with SEN may be more likely to have lower career aspirations and 
outcomes, are their career aspirations more or less important in predicting their future educational and occupational pathways compared to those without SEN? While qualitative studies have emphasized the importance of early career planning for adolescents with SEN (e.g., Beyer, Kaehne, Grey, Sheppard, \& Meek, 2008), there is less quantitative work investigating the association between the early career aspirations of young people with SEN and their later outcomes. In particular, we found no recent empirical studies comparing the association between early career aspirations and later educational and employment outcomes for adolescents with and without SEN. Such information would enhance our understanding of what early factors we can put in place to support young people with SEN as they prepare to make their school-to-work transition.

Using a nationally representative study of adolescents in England, this study investigates the role of career aspirations at age 14 in predicting later educational and occupational outcomes from ages 16 to 20 of adolescents with SEN in comparison to those without SEN. For our outcomes, we focus on two important indicators of successful development for both education and employment: GCSE and NEET (not in education, employment or training) status. In England, GCSE acts as a gateway to later educational opportunities, offering students who have $5 \mathrm{~A}-\mathrm{C}$ 's further study in preparation for university enrollment. NEET is an important indicator of worklessness and school disengagement for young people and is associated with worse labor market outcomes in the longer term (Britton, Gregg, Macmillan, \& Mitchell, 2011; Dorsett, R., \& Lucchino, 2015). In England, young people with SEN are half as likely to achieve 5 or more General Certificate of Secondary Education (GCSE) exam grades A*-C and are more than twice as likely to be NEET by the time they leave school than their peers without SEN (Department of Education, 2011). Young people who previously held a 
statement of SEN are also less likely to continue in education after compulsory schooling age (i.e., age 16) than those who have never been categorized as having SEN (DfE, 2011). Below, we provide a definition of SEN, then explain our theoretical framework and research hypotheses.

\section{Defining SEN}

Defining SEN is not a straightforward endeavor, as definitions vary across countries, comprise multiple manifestations and measures. According to the Office for Economic Collaboration and Development, a child is identified as having SEN "if he or she is not able to benefit from the school education made generally available for children of the same age without additional support or adaptions in the context of studies" (OECD, 2012). The classification of SEN can cover a range of needs including physical or mental disabilities, cognition or educational impairments. Country-specific definitions of SEN vary according to whether children with certain disabilities are included in the classification and depend on country specific legislation. Thus, in some countries, such as Greece and Sweden, only children attending special programmes in special schools are identified as having SEN, and not those attending mainstream school. In the UK, in contrast, most children with SEN are integrated into mainstream schooling, except those with more complex or profound needs requiring a special school (Ofsted, 2010). According to a review conducted by the UK Office for Standards in Education, Children's Services and Skills, "pupils have special educational needs if they have learning difficulties that need special educational provision. They have learning difficulties if they find it much harder to learn than most pupils of the same age or they 
have disabilities that make it much more difficult for them in school" (Ofsted, 2010)ํ. Their special needs can include profound and multiple learning difficulty; behavior, emotional and social difficulty; and speech, language and communication needs. The evidence presented in the review shows that in 2006 about $19 \%$ of pupils in England were identified as having SEN. Especially at risk were boys, children in receipt of free school meals and ethnic minorities.

In the following study, the operationalization of SEN is based on the identification and provision of additional educational support at school. In the LSYPE, linkage is available to other administrative data, such as the National Public Database (NPD), which includes individual school data including national assessments for all children in England. Using the NPD, we identified students with SEN who attended mainstream schools, excluding those who attended special schools for children with profound and severe needs and those with physical disabilities.

\section{Theoretical Models of Career Development in Adolescence}

Adolescence represents an important developmental period when young people consider their educational trajectories and contemplate their future career choices. Early decisions set in motion a series of later options, leading to either greater opportunities or restricted pathways. Within ecological models of career development, it is recognized that the expression and realization of occupational choice has to be understood against the backdrop of socio-cultural constraints and opportunities, and perceptions of viable options within these constraints (Schoon \& Eccles, 2014). Formulating aspirations regarding different educational and vocational pathways is a

\footnotetext{
${ }^{1}$ In Scotland, however, the language and understanding of need is different and is referred to as Additional Support for Learning (ASL) in recognition that any young person, at any time, could have an additional need.
} 
key developmental task of adolescents, and career theorists view career aspirations as a central component of vocational identity formation (Erikson, 1968; Skorikov \& Vondracek, 2011). Career aspirations represent adolescent's conceptualization of their own talents, goals and interests and serve as a vehicle through which they may actualize their emerging vocational identity. Career aspirations, therefore, can act as compass to navigate one’s occupational trajectory.

Gottfredson's theory of circumscription and compromise (1981; 2005) describes how career choice develops across childhood and adolescence. As children mature into adolescents, their personal identities and external realities shape their career aspirations. Their self-concept in terms of their interests, values and talents plays an important role in occupational choice, yet perceived barriers such as the cost and effort of obtaining relevant education, training and employment may force compromise in their aspirations. Gottfredson posits that there may be certain boundaries of tolerable effort in career choice. In other words, individuals may dismiss occupations if they appear too difficult to obtain with reasonable effort or present too high a risk of failure. The boundary of tolerable effort is largely based on one's own academic ability.

Motivation theories also underline the importance of personal and family factors in shaping adolescents' career aspirations. Social Cognitive Career Theory (SCCT) asserts that if individuals believe that they can succeed in an occupation, they are more likely to pursue it (Lent et al., 2005). In a similar vein, Eccles' expectancy-value model emphasizes one's own self-concept of ability, motivation and perceived cost as important predictors of behavioral choice and later performance (Eccles et al., 1983; Eccles \& Wigfield, 2002). The primacy of parents is also highlighted as shaping adolescents' aspirations (Eccles, 1993; Eccles, 2006). In addition to structural features of the family, parental expectations have been shown to contribute to the development 
of adolescents' aspirations and choices (Eccles, Barber, \& Jozefowicz, 1999; Jodl et al., 2001; Schoon, 2010). These expectations, in turn, are affected by previous experiences and socialization influences such as prior achievement. For example, adolescents from higher socioeconomic backgrounds tend to have higher occupational aspirations than their counterparts from lower socio-economic backgrounds, even after controlling for academic ability - and so do their parents (Gutman \& Schoon, 2012; Mau \& Bikos, 2000; Schoon \& Parsons, 2002).

The influence of socio-demographic variables such as gender and race/ethnicity have also been highlighted. These are significant variables for career aspirations as they influence individual's access to resources and opportunities, their experiences of discrimination and compromises in their career choice (Lent, Brown, \& Hackett, 2005; Gottfredson, 2005). Previous research has shown that female adolescents tend to report occupational aspirations equal to or higher than male adolescents (Gutman \& Schoon, 2012; Mello, 2008; Rojewski \& Kim, 2003; Schoon, 2006), although no practical gender differences have been found in the career aspirations of adolescents with learning disabilities (Rojewski, 1996). In terms of race/ethnicity, studies using the LSYPE have found that ethnic minority adolescents living in England tend to have higher career aspirations compared to their White British counterparts (Gutman, Sabates, \& Schoon, 2014; Gutman \& Schoon, 2012; Strand, 2007), which has been explained by differences in cultural attitudes towards higher education (Torgerson et al, 2008), and the expectation that better qualifications will reduce the effect of possible future racial discrimination in the labor market (Connor, Tyers, Modood, \& Hillage, 2004).

There are also different approaches to examining career aspirations. Many empirical studies have analyzed career aspirations as a dichotomous construct coded according to prestige or socioeconomic level (i.e., high, professional versus low, manual 
occupations). However, not all adolescents have definitive ideas concerning what they want to do for their future jobs. For example, research on adolescents in England finds that 20\% express uncertainty in their career aspirations and do not know what sort of career they wish to have in the future (Gutman \& Schoon, 2012). Students with learning difficulties have been shown to be more indecisive about future occupational alternatives compared to their peers without (Rojewski, 1996). Nevertheless, the relationship between uncertainties in career aspirations and later educational and employment outcomes have rarely, if ever, been examined in quantitative research for adolescents with SEN.

\section{Current Study}

Drawing upon the Longitudinal Study of Young People in England (LSYPE), this study examines the career aspirations of adolescents designated as having SEN, who attend mainstream schools in England. The research aims are twofold: (1) to provide descriptive information on the career aspirations, sociodemographic variables and outcomes of adolescents with SEN in comparison to those without SEN and (2) to analyse whether career aspirations at age 14 are more or less important in predicting later educational and employment outcomes from ages 16 to 20 for adolescents with SEN in comparison to those without.

In recognition of Gottfredson's boundary of tolerable effort (2005), as well as the notion of perceived costs in Eccles' expectancy-value model (Eccles \& Wigfield, 2002) and in light of previous evidence (Rojewski, 1996; 1999; Rojewski et al., 2014); we expect (1) that adolescents with SEN will have lower and more uncertain career aspirations than their peers without SEN. In consideration of previous evidence showing that career aspirations are not necessarily predictive of attainment in disadvantaged adolescents (Carter-Wall \& Whitfield, 2012; Gutman \& Akerman, 2008), 
we also postulate (2) that the association between career aspirations and later outcomes might be stronger for those without SEN, as they may have greater access to opportunities and be less likely to experience barriers to their aspirational fulfilment compared to those with SEN.

Given the importance of prior academic ability, parental expectations, academic self-concept, school motivation and sociodemographic characteristics highlighted in socio-ecological theories of career development (e.g., Eccles et al., 1983; Lent et al., 2005; Schoon \& Eccles, 2014), these covariates are taken into account in the analyses. Furthermore, the study takes a multi-dimensional view of career aspirations, including both prestige level and uncertainty.

\section{Method}

\section{Data Source}

The study draws on data collected for the LSYPE (Department for Education, National Centre for Social Research, 2012), a panel study of young people in Year 9 (age 15) in all secondary schools in England in February 2004 and born between 1st of September 1989 and 31st of August 1990. The achieved sample consisted of 15,570 pupils drawn from over 658 secondary schools. Annual face-to-face interviews were conducted with adolescents and their parents since 2004. There are seven waves of data covering ages 14 to 20 . As all longitudinal studies, LSYPE experienced sample loss between the multiple waves. Special sample weights which are calculated and available from the LSYPE website were applied. These weights correct for differential selection probabilities and non-response bias.

\section{Analytic Sample}

The analytic sample used for the study comprises adolescents who attended mainstream schools, excluding those who attended special schools catering for students 
designated as having SEN due to severe learning difficulties, physical disabilities or behavioral problems $(n=139)$. Further excluded were adolescents who attended mainstream schools but whose specific SEN related to having physical disabilities, being gifted or talented only or not having English as a first language using parent-reported data at Waves 1 and $2(n=389)$. This provided a final analytic sample of 9,966 adolescents with complete data on SEN provision and Wave 1 career aspirations.

\section{Measures}

SEN provision. Students with special educational needs comprise those identified to be in need of School Action (SA), School Action Plus (SAP) or a Statement of SEN. As defined by the SEN code of practice in England (Department for Education and Skills, 2001), SA is where the teacher or Special Educational Needs Coordinator (SENCO) decides to provide support for the child additional to or different from the school's usual differentiated approach to help children learn, SAP is where the school consults specialists and requests help from external services and a Statement is where the child requires support beyond that which the school can provide and the local authority arranges and funds appropriate provision such as classroom assistant. In the analytic sample, $84 \%$ did not have any SEN ( $n=8,449), 10 \%$ had SA ( $n=988), 4 \%$ had SAP $(\mathrm{n}=384)$ and $2 \%$ had a Statement $(\mathrm{n}=145)$.

Adolescent Gender. The gender of the adolescent was coded as (0) female versus (1) male.

Adolescent Race/Ethnicity. The ethnicity of the adolescent was coded as (1) ethnic minority versus (0) White. Given the ethnic diversity in England, the different ethnic groups were too numerous and the n of each group was too small to examine differences among the groups individually. 
Prior Academic Performance at age 11. Academic performance was obtained from the NPD and calculated using a standardized average of math and English scores in national curriculum tests given at age 11 .

Parental Highest Occupational Status. Parental occupational status was assessed at Wave 1 based on the Standard Occupational Classification (OPCS, 1991) and was coded into three occupational categories of increasing occupational status $(1=$ unskilled occupations, 2 = skilled occupations, 3 = professional and managerial occupations).

Parental Highest Educational Status. Parental educational status was assessed at Wave 1 and was coded into five categories of increasing educational attainment $(1=$ less than secondary school, 2 = Graduate Certificate of Secondary Education (GCSE) completion, 3 = A-levels or equivalent, 4 = less than university, 5 = university degree or higher).

Parental Marital Status. Parental marital status was assessed at Wave 1, where 1= married; 0 = single, divorced or widowed .

Parental Educational Expectations. Parents were asked with a single item at Wave 1 (age 14) what they expected their child to do when reaching school leaving age (after the school year when the student is age 16). Responses included ( 1 = continue in education, 2 = get an apprenticeship, 3 = learn a trade, 4 = get a job, 5 = something else). High parental expectations were assigned to parents who expected the cohort member to continue in education after age $16(1=$ continue in full-time education; $0=$ not continue in education).

School Motivation. (alpha $=.77$ ) Adolescents were asked seven items at Wave 1 (age 14). Items included: "I am happy when I am at school." "School is a waste of time 
for me (recoded)." "The work I do in lessons is interesting to me." and "I do not like school (recoded)." (1=strongly disagree, 2=disagree, 3=agree, 4= strongly agree). The validity of the school motivation scale has been demonstrated in studies linking it to educational and occupational attainment (Schoon, 2008), especially among disadvantaged adolescents (Duckworth \& Schoon, 2012).

Academic Self-Concept. (alpha $=.76)$. Adolescents were asked six items at Wave 1 (age 14). Items included: "I am good at math." "I am good at English." and "I am good at science." (1 = not good at all, 2 = fairly good, 3 = good, 4 = very good); "I am good at school work." and "My teachers think I am good at school work." (1 = not good at all, $2=$ below average, 3 = average or above average, 4 = very good) and "I get good marks for my work." (1=strongly disagree, 2=disagree, 3=agree, 4= strongly agree).

Career Aspirations. The starting point was a question asked of all adolescents at age 14 (Wave 1): "Do you have any ideas of the kind of job you want to do after fulltime education?" Those who answered 'no' were defined as having uncertain career aspirations. For those who knew the kind of job they wanted to do after full-time education, an open-ended question was then asked to describe this job. Next, each of their career aspirations were coded according to the following three categories: professional/managerial occupations, skilled occupations (e.g., technical and administrative) and semi-skilled and unskilled (e.g., service and operative). The use of a one-item measure of occupational aspirations is justified, since expressed interest in a profession has been shown to predict the category of a person's future occupation (Holland, Gottfredson, \& Baker, 1990). 
Academic Performance at age 16. A measure of academic performance was calculated using total capped GCSE scores taken from the NPD in individual academic subjects given at the end of Key Stage 4 .

Not in Education, Employment or Training (NEET) from ages 16 to 20. The total number of months being NEET from September 2006 (two months after the respondents completed compulsory education) until May 2010 (the first month of interviews for Wave Seven) was calculated.

\section{Analytic Plan}

First, descriptive statistics are presented. For career aspirations, chi-squared tests were performed to assess differences among the categories of SEN provision. Post-hoc tests were then conducted to compare all possible pairwise differences among the categories. We used the Bonferroni correction to adjust for multiple comparisons. An analysis of variance (ANOVA) was conducted to assess differences among the categories of SEN provision for the covariates and outcomes. Again, post-hoc tests were conducted using the Bonferroni correction to adjust for multiple comparisons.

Second, a series of multiple regression models were run for both academic performance at age 16 and months being NEET from ages 16 and 20. For the categorical measures, dummy codes were created for the regression models. For parental occupational status, we differentiated between parents having a professional/managerial position (which was the reference category) versus parents with skilled and unskilled occupations. For career aspirations, we differentiated between aspirations for professional/managerial jobs (reference category), skilled jobs, unskilled jobs and uncertain aspirations. For SEN, we identified adolescents with no SEN (reference category), those with SA, and those with either SAP or a Statement 
(combining the two categories). A combined SAP/Statement category was justified for four reasons: First, SAP and Statement represent those who receive specialist provision. Second, both SAP and Statement had small sample sizes, especially across the different categories of career aspirations (see Tables 1 and 2). Third, there were no significant differences in percentages of adolescents with either SAP or a Statement who had professional/managerial, skilled or unskilled career aspirations, although those with a Statement had more uncertain career aspirations than those with SAP (see Table 1). Lastly, there were no significant differences in the later educational and employment outcomes of adolescents with either SAP or a Statement, although those with SA had significantly better outcomes compared to both groups (see Table 2).

\section{Results}

\section{Descriptive Statistics}

Table 1 presents the percentages of adolescents who aspire to unskilled, skilled or professional careers or those who are uncertain according to the different categories of SEN provision. A chi-square test of independence between SEN provision and career aspirations was statistically significant, $\mathrm{X} 2(9, \mathrm{~N}=9966)=131.87, \mathrm{p}<.001$. Post-hoc analyses revealed there were significant differences in aspirations among the categories of SEN, with adolescents with a Statement being more likely to report uncertain aspirations than adolescents without SEN, those with SA or those with SAP (see Table 1). Adolescents with SEN (including those with SA, SAP or a Statement) were less likely to aspire to a professional /managerial job and more likely to aspire to a skilled job than those without SEN. Those with SAP or a Statement were less likely to aspire to a professional/managerial job compared to those with SA. Adolescents with SA or SAP were more likely to aspire to an unskilled job compared to those without SEN. 
Table 2 presents the means and SD of the covariates and outcomes according to the different categories of SEN provision. There were significant differences among the categories of SEN for all of the covariates and outcomes. Post-hoc analyses revealed significant differences between the specific categories of SEN. Adolescents with SEN were more likely to be male than those without SEN and the percentage of males significantly increased with greater provision. Adolescents with SA or SAP were more likely to be ethnic minorities than those without SEN or those with a Statement. Parents of adolescents with SEN had lower occupational status and educational attainment than parents of adolescents without SEN, and were less likely to be married, although there were no differences in parental marital status between those with a Statement and those without SEN. Parents of adolescents with SEN also had lower educational expectations for them and adolescents with SEN reported having lower school motivation and a lower academic self-concept than those without SEN. Adolescents with SEN also had lower levels of academic achievement at both 11 and 16 years, as well as more months being NEET from ages 16 to 20 than those without SEN. There were, however, differences in academic attainment and NEET status among those with SEN. Adolescents with either SA or SAP had higher achievement at age 11 than those with a Statement and adolescents with SA had higher achievement at age 16 than those with either SAP or a Statement . Moreover, those with either SAP or a Statement had more months at being NEET from ages 16 to 20 than those with SA.

\section{Career Aspirations as Predictors of Educational and Employment Outcomes}

As shown in Tables 3 and 4, we ran a series of regression models using career aspirations as predictors of later educational and employment related outcomes. For both, we adopted a hierarchical strategy to assess different underlying processes. In a first model, the relationship between SEN provision and the later educational or employment outcome was examined, taking into account the covariates (i.e., 
adolescents' gender, ethnicity and prior academic performance; parental occupational, educational and marital status; parental expectations and adolescents' academic selfconcept and school motivation). In a second model, career aspirations were entered. This provided the association between career aspirations and the later outcome, taking into account the covariates and adolescents' SEN provision. The last model examined whether the relationship between career aspirations and the later outcome was stronger for those with SEN compared to those without SEN. In order to do this, a series of interaction terms between SEN provision and career aspirations were entered into the regression models. Figures 1 and 2 present the significant interactions between SEN provision and career aspirations for GCSE scores and months of NEET, respectively. In the figures, the average scores on the outcomes were calculated for the average person with varying SEN provision and career aspirations.

Academic Performance at Age 16. As shown in the first model, adolescents with SEN had lower GCSE scores at age 16 than those without SEN, taking into account the covariates (see Table 3). In the second model, adolescents who reported career aspirations for skilled or unskilled jobs had lower GCSE scores at age 16 than those with aspirations for professional/managerial jobs, taking into account the covariates. There were no differences in the GCSE scores of adolescents who reported uncertain career aspirations compared to those who reported aspirations for professional/managerial jobs, however.

As shown in the third model, there were significant interactions between SEN provision and career aspirations for adolescents with SAP/Statement. For adolescents with SAP/Statement, those who reported skilled, unskilled or uncertain career aspirations had significantly lower GCSE scores than those who reported professional/managerial aspirations; while there were little or no differences in the GCSE scores of adolescents without SEN, regardless of their career aspirations (see Figure 1). As shown in Figure 
1, the total GCSE score of the average young person with SAP/Statement who had aspirations for a skilled job was 31.62 points lower (equivalent to one-half of an extra GCSE exam at grade $\mathrm{A}^{*}$ ) than the average young person with SAP/Statement who reported professional/managerial aspirations, while the difference between adolescents without SEN who reported professional/managerial versus skilled aspirations was 4.29 points. For those adolescents with SA, there were no significant interactions, only significant main effects.

Months being NEET from Ages 16 to 20. As shown in the first model, adolescents with SEN experienced more months of being NEET than those without SEN, taking into account the covariates (see Table 4). In the second model, there were no differences in the number of months of being NEET for those with skilled, unskilled or uncertain aspirations compared to those with professional/managerial aspirations, taking into account the covariates.

As shown in the third model, there were significant interactions between SEN provision and career aspirations for adolescents with SAP/Statement. For adolescents with SAP/Statement, those with aspirations for skilled, unskilled or uncertain jobs experienced more months of being NEET compared to those with professional/managerial aspirations, while there were negligible differences in the number of months being NEET for those without SEN, regardless of their career aspirations (see Figure 2). As shown in Figure 2, the average young person with SAP/Statement who had skilled aspirations experienced 2.75 additional months of being NEET than the average young person with SAP/Statement who reported professional/managerial aspirations, whereas there was no difference between adolescents without SEN who reported skilled versus professional/managerial 
aspirations. As with Academic Performance at age 16, there were no significant interactions for those adolescents with SA, only significant main effects.

\section{Discussion}

This study highlights the importance of career aspirations for adolescents with SEN. Adolescents with SEN had lower and more uncertain career aspirations at age 14, as well as worse educational and employment outcomes from ages 16 to 20 than adolescents without SEN. Furthermore, the consequences of their aiming high, low or being uncertain played a more significant role in their later outcomes compared to those without SEN. Findings underline the importance of helping adolescents with SEN identify their career aspirations in early adolescence and adopt appropriate strategies to encourage them to reach their potential.

This study specified the percentage of adolescents with SEN who aspire to different status occupations in comparison to those without. Compared to those without SEN, a lower percentage of those with SEN hoped to have professional/managerial careers, while a higher percentage aspired for skilled and unskilled jobs. There were differences in the aspirations of adolescents with SEN, and a greater percentage of adolescents with a Statement reported uncertain career aspirations compared to those with SA, SAP or no SEN. The findings potentially reflect the perceived barriers to eventual occupational attainment, as suggested in theories emphasizing boundaries of tolerable effort (Gottfredson, 1981, 2005), or perceived costs (Eccles, 1993, 2006) and associated uncertainties. In interpreting the findings, one has to take into consideration that aspirations for skilled or unskilled jobs are not necessarily a negative choice, especially in the light of changing employment opportunities and existing constraints. There is not an unlimited supply of high status occupations, and in addition to a rising demand for highly qualified workers, recent 
labour market changes have also led to an increasing demand for low-skilled workers, mainly in the service sector (Goos \& Manning, 2007; Karoly, 2009).

Adolescents with SEN showed worse academic performance at ages 11 and 16 and had more months of NEET from ages 16 to 20 than their counterparts without SEN. Young people with SEN also were less motivated in school, had lower confidence in their academic ability and had parents who had lower expectations for their educational future compared to their peers without SEN. These findings possibly indicate the effects of socio-cultural constraints and perceptions of limited opportunities (Schoon \& Eccles, 2014); as well as social bias, discrimination or structural barriers associated with disability status (Rojewski, 1996, 1999), also emphasized in the social-cognitive theory of career development (Lent et al., 2005). Yet, those with SA had higher academic attainment than those with SAP or a Statement, which may reflect that those with SA have less serious needs not requiring specialist provision in comparison to those with SAP or a Statement.

We also found that adolescents who were designated as having SEN were predominately male (confirming findings from the 2010 OSTED review), and the proportion of males increased with greater provision of specialist care, which might suggest raised attention to boys with special needs. Moreover, adolescents with SEN tended to be from a less privileged background, pointing maybe to the cumulation of disadvantage. Furthermore, there were more ethnic minorities who were designated as SA, compared to their peers without SEN, but not compared to those with SAP or a Statement. Thus, ethnic minorities do not appear to be overrepresented in the categories of SEN with specialist provision in this sample. This again confirms previous findings of the Ofsted review (2010) that ethnic minority students were only overrepresented among those SEN categories without statements at secondary schools. 
Together, these findings present a portrait of adolescents who are most at risk of having specialist provision for SEN - boys from lower socio-economic backgrounds. Together, these findings highlight the variations in attainments among adolescents with SEN, associated with possibly reduced access to opportunities and potential barriers facing the fulfilment of their ambitions.

In support of Eccles' expectancy-value model (Eccles et al., 1983; Eccles \& Wigfield, 2002), we found that adolescents' own self-concept of ability, school motivation and parental expectations were signficant predictors of their later academic performance, while school motivation and parental expectations predicted months of NEET from ages 16 to 20 . Regarding the predictive value of early career aspirations on later outcomes, there was a significant association between career aspirations and academic performance at age 16, after controlling for SEN status, socio-demographic factors, parents' educational expectations, prior academic ability, school motivation and academic self-concept. Adolescents with aspirations for skilled or unskilled jobs had lower academic performance at age 16 than those with professional/managerial aspirations. There was, however, no significant association between uncertain career aspirations and academic performance at age 16 , and between career aspirations of any type and the number of months being NEET between ages 16 to 20. Moreover, we find significant interactions between career aspirations and the SAP/Statement classifications of SEN, suggesting that adolescents who were designated as having either SAP or a Statement and who expressed skilled/unskilled or uncertain aspirations had lower GCSE scores and a more extended experience of NEET than those in the same situation with aspirations for professional or managerial jobs. The findings highlight the potential motivational role of high aspirations among young people with high levels of specialist provision (SAP or Statement), giving them a special push to attain educational 
qualifications and avoid precarious transitions. They could however also indicate the benefits of specialist attention and advice encouraging those with special needs to aim high and enabling them to do better than expected. In contrast, these significant interactions showed that the career aspirations of those without SEN had little discernable impact on their later outcomes when important covariates were taken into account, reflecting their academic abilities and parents' expectations of them as well as their own self-conceptions and motivation which together likely drive their efforts for success. Furthermore, there were no significant interactions between career aspirations and the SA classification of SEN, showing that the strength of the association between career aspirations and later educational and employment outcomes was similar for those with SA in comparison to those without SEN.

We expected that career aspirations would be more predictive of later outcomes for those without SEN rather than those with SEN, yet found the opposite effect. Early career aspirations played a more important role in the educational and employment outcomes of adolescents with SAP or a Statement in comparison to those without SEN or SA. Thus, having high career aspirations appears to have a protective effect for adolescents with SAP or a Statement, perhaps by offering a compass to guide and motivate their efforts toward the fulfillment of a lofty future goal (Vondracek, 2001). It may also signify an individual's willingness to go beyond their boundaries of tolerable effort (Gottfredson, 2005), to seek out new opportunities and surmount existing barriers. However, this finding was not pertinent for those with SA, perhaps reflecting that those with SA might have slightly better educational and occupational opportunities than those with SAP or a Statement, whatever their aspirations.

\section{Limitations}


This study has several limitations that need to be considered in light of the findings. First, the study investigated the career aspirations of adolescents with SEN at only one point in time (age 14), thus limiting the understanding of the processes which help to form their aspirations and whether their aspirations change as they proceed through schooling. However, other studies have shed light on these areas of research (Rojewski, Lee, Gregg, \& Gemici, 2012a, 2012b). On average, occupational aspirations of young people with disabilities tend to increase during high school, but then decrease after school completion (Rojewski et al., 2012a). Second, although a number of personal and family covariates were included, other family and school factors are likely to play a role in students' aspirations and attainment, such as parental involvement and teacher support. This omission may explain the low $\mathrm{R}^{2}$, especially for the model predicting NEET. Lastly, the identification of adolescents with SEN can be challenging using nationally representative data not specifically designed for this purpose. Given the intricacies involved in identifying children and adolescents with SEN, it is possible that some adolescents were misidentified. In order to reduce this possibility, we excluded those children who attended special schools and were identified by their parents as having SEN due to physical difficulties, being bright or gifted only or not having English as a first language. Despite these methodological concerns, LSYPE provides unique access to a nationally representative sample of adolescents with data from ages 14 to 20, allowing the examination of career development in this much understudied population.

\section{Conclusions}

This study aids in the understanding of the complex relationship between career aspirations and later educational and employment outcomes for adolescents with SEN. As this study suggests, aspirations do matter for young people with SEN, even more so 
perhaps than their peers without SEN. Findings indicate that young people with SEN would benefit from having career counseling in early adolescence to work out possible career options for their future which maximize their potential. In light of previous research (Eccles et al., 1999; Jodl et al., 2001; Schoon, 2010), involving parents and teachers as key players in supporting and encouraging the fulfilment of their ambitions also seems promising. In addition, opportunities which may reduce perceptions of socio-cultural constraints and barriers such as work skills training, internships and apprenticeships may further encourage young people with SEN to have high aspirations and to pursue them.

Future studies should examine the processes which can circumvent low, uncertain aspirations in more detail and encourage adolescents with SEN to aim toward their highest goals. Research which investigates the trajectories of adolescents with SEN, as they navigate through education and training, would provide more information on how best to support them through the process of becoming a young adult and to realize their ambitions. 


\section{References}

Beyer, S., Kaehne, A., Grey, J., Sheppard, K. \& Meek, A. (2008). The transition of young people with learning disabilities to employment: what works? Journal of Developmental Disabilities, 14(1), 85-94.

Britton, J., Gregg, P., Macmillan, L., \& Mitchell, S. (2011). The early bird... preventing young people from becoming a NEET statistic. Report commissioned by Praxis.

Bronfenbrenner, U., \& Ceci, S. J. (1994). Nature-Nurture Reconceptualized in Developmental Perspective - a Bioecological Model. Psychological Review, 101, 568-586.

Carter-Wall, C., \& Whitfield, G. (2012). The role of aspirations, attitudes and behaviour in closing the educational attainment gap. In Gorard, S. Huat See, B. and Davies, P. (Eds.), The Impact of Attitudes and Aspirations on Educational Attainment and Participation, Joseph Rowntree Foundation.

Casey, L., Davies, P., Kalambouka, A., Nelson, N., \& Boyle, B. (2006). The influence of schooling on the aspirations of young people with special educational needs. British Educational Research Journal, 32(2), 273-290.

Clausen, J. A. (1993). American lives: looking back at the children of the Great Depression. Berkley: University of California Press.

Coll, C. G., \& Marks, A. K. (Eds.). (2012). The immigrant paradox in children and adolescents: Is becoming American a developmental risk? . Washington, DC, US: American Psychological Association http://dx.doi.org/10.1037/13094-000

Connor, H., Tyers, C., Modood, T., \& Hillage, J. (2004). Why the difference: a closer look at ethnic minority students and graduates (No. 552). Research report. 
Croll, P. (2008). Occupational choice, socio-economic status and educational attainment: a study of the occupational choices and destinations of young people in the British Household Panel Survey. Research Papers in Education, 23(3), 243-268.

Cross, C. T., \& Donovan, M. S. (Eds.) (2002) Minority Students in Special and Gifted Education. National Academies Press.

Department for Education. (2011). Support and Aspiration: A New Approach to Special Educational Needs and Disability. A Consultation. London: DfE.

Department for Education, National Centre for Social Research. (2012). First Longitudinal Study of Young People in England: Waves 1-7, 2004-2010. [data collection]. 12th Edition. UK Data Service. SN: 5545, http://dx.doi.org/10.5255/UKDA-SN-5545-3.

Department for Education and Skills (2001). Special Eductional Needs: Code of Practice. London, DFES.

Dorsett, R., \& Lucchino, P. (2015). The School-to-Work Transition: An overview of two recent studies (No. 445). National Institute of Economic and Social Research.

Duckworth, K., \& Schoon, I. (2012). Beating the odds: Exploring the impact of social risk on young people's school-to-work transitions during recession in the UK. National Institute Economic Review, 222(October), 38-51.

Eccles, J. S. (2006). Families, schools, and developing achievement-related motivations and engagement. In J. E. Grusec \& P. D. Hastings (Eds.), Handbook of socialization: Theory and research (pp. 665-691). New York: Guilford.

Eccles, J. S. (1993). School and family effects on the ontogeny of children's interests, selfperceptions, and activity choice. In J. Jacobs (Ed.), Nebraska Symposium on 
Motivation, 1992: Developmental perspectives on motivation (pp. 145-208). Lincoln: University of Nebraska Press.

Eccles, J., Adler, T. F., Futterman, R., Goff, S. B., Kaczala, C.M., Meece, J. L., et al. (1983). Expectations, values and academic behaviors. In J. T. Spence (Ed.), Perspective on achievement and achievement motivation (pp. 75-146). San Francisco: W. H. Freeman.

Eccles, J. S., Barber, B., \& Jozefowicz, D. (1999). Linking gender to education, occupation, and recreational choices: Applying the Eccles et al. model of achievement-related choices. In W. B. Swann, J. H. Langlois, \& L. A. Gilbert (Eds.), Sexism and stereotypes in modern society: The gender science of Janet Taylor Spence (pp. 153-192). Washington, DC: APA Press.

Eccles, J.S. \& Wigfield, A. (2002) Motivational beliefs, values and goals. Annual Review of Psychology 2002, 53, 109-132.

Elder, G. H. (1998). The life course as developmental theory. Child Development, 69, 112.

Erikson, E. H. (1968). Identity, youth, and crisis. New York: W. W. Norton.

Goos, M., \& Manning, A. (2007). Lousy and lovely jobs: the rising polarization of work in Britain. Review of Economics and Statistics, 89, 118-133.

Gottfredson, L. S. (1981). “Circumscription and Compromise: A Developmental Theory of Occupational Aspirations." Journal of Counseling Psychology (Monograph), 28, 545-579.

Gottfredson, L. S. (2004). Using Gottfredson's Theory of Circumscription and Compromise in Career Guidance and Counseling. In S. D. Brown and R. W. Lent 
(Eds), Career Development and Counseling: Putting Theory and Research to Work (p. 71-100), New York: Wiley.

Gregg, N., Coleman, C., Davis, M., Lindstrom, W., \& Hartwig, J. (2006). Critical issues for the diagnosis of learning disabilities in the adult population. Psychology in the Schools, 43(8), 889-899.

Gutman, L., \& Akerman, R. (2008). Determinants of aspirations [Wider Benefits of Learning Research Report No. 27]. Centre for Research on the Wider Benefits of Learning, Institute of Education, University of London.

Gutman, L. M., Sabates, R., \& Schoon, I. (2014). Gender differences in young people. In I. Schoon and J. S. Eccles (Eds.), Gender differences in aspirations and attainment (pp. 161-181). Cambridge: Cambridge University Press.

Gutman, L. M., \& Schoon, I. (2012). Correlates and consequences of uncertainty in career aspirations: Gender differences among adolescents in England. Journal of Vocational Behavior, 80(3), 608-618.

Hitchings, W. E., Luzzo, D. A., Ristow, R., Horvath, M., Retish, P., \& Tanners, A. (2001). The career development needs of college students with learning disabilities: In their own words. Learning Disabilities Research \& Practice, 16(1), 8-17.

Hotchkiss, L., \& Borow, H. (1996). Sociological perspectives on work and career development. In D. Brown, L. Brooks, \& Associates (Eds.), Career choice and development: Applying contemporary theories to practice (3rd ed., pp. 281-334). San Francisco: Jossey-Bass.

Holland, J. L., Gottfredson, G. D., \& Baker, H. G. (1990). Validity of vocational aspirations and interest inventories: Extended, replicated, and reinterpreted. Journal of Counseling Psychology, 37(3), 337-342. 
Jodl, K. M., Michael, A., Malanchuk, O., Eccles, J. S., \& Sameroff, A. (2001). Parents' roles in shaping early adolescents' occupational aspirations. Child development, 12471265.

Karoly, L. A. (2009). The future at work: Labor-market realities and the transition to adulthood. In I. Schoon \& K. R. Silbereisen (Eds.), Transitions from school to work. Globalization, individualization, and patterns of diversity (pp. 352-384). New York: Cambridge University Press.

Lee, I. H., \& Rojewski, J. W. (2013). Brief report: A growth mixture model of occupational aspirations of individuals with high-incidence disabilities. Journal of Adolescence, 36(1), 233-239.

Lent, R. W., Brown, S. D., \& Hackett, G. (1996). Career development from a social cognitive perspective. In D. Brown, L. Brooks, \& Associates (Eds.), Career choice and development: Applying contemporary theories to practice (3rd ed., pp. 423475). San Francisco: Jossey-Bass.

Lent, R. W., Brown, S. D., Sheu, H.-B., Schmidt, J., Brenner, B. R., et al. (2005). Social cognitive predictors of academic interests and goals in engineering: Utility for women and students at historically black universities. Journal of Counseling Psychology, 52(1), 84-92. doi:10.1037/0022-0167.52.1.84

Mau, W. C., \& Bikos, L. H. (2000). Educational and vocational aspirations of minority and female students: A longitudinal study. Journal of Counseling and Development, 78, 186-194.

Mello, Z. R. (2008). Gender variation in developmental trajectories of educational and occupational expectations and attainment from adolescence to adulthood. Developmental Psychology, 44(4), 1069-1080. 
OECD. (2012). Special Educational Needs (SEN) OECD Child well-being Module CX3.1. Retrieved from

Ofsted. (2010). Children with special educational needs 2010: an analysis. Retrieved from London:

Rojewski, J. W. (2005). Occupational aspirations: Constructs, meanings, and application. Career development and counseling: Putting theory and research to work, 131-154. Rojewski, J. W. (1999). Occupational and educational aspirations and attainment of young adults with and without LD 2 years after high school completion. Journal of Learning Disabilities, 32(6), 533-552.

Rojewski, J. W. (1997). Characteristics of Students Who Express Stable or Undecided Occupational Expectations during Early Adolescence. Journal of Career Assessment, $5(1), 1-20$.

Rojewski, J. W. (1996). Educational and occupational aspirations of high school seniors with learning disabilities. Exceptional Children, 62(5), 463-476.

Rojewski, J.W., 1996. Occupational aspirations and early career-choice patterns of adolescents with and without learning disabilities. Learning Disability Quarterly, 19(2), pp.99-116.

Rojewski, J. W., \& Kim, H. (2003). Career choice patterns and behavior of work-bound youth during early adolescence. Journal of Career Development, 30, 89-108.

Rojewski, J. W., Lee, I. H., \& Gregg, N. (2014). Intermediate work outcomes for adolescents with high-incidence disabilities. Career Development and Transition for Exceptional Individuals, 37, 106-118.

Rojewski, J. W., Lee, I. H., Gregg, N., \& Gemici, S. (2012a). Development patterns of occupational aspirations in adolescents with high-incidence disabilities. Exceptional Children, 78(2), 157-179. 
Rojewski, J. W., Lee, I. H., Gregg, N., \& Gemici, S. (2012b). Prominent factors affecting the formation and longitudinal growth patterns of the career aspirations of adolescents with high incidence disabilities. Exceptional Children, 78(1), 157-178.

Rojewski, J. W., \& Yang, B. (1997). Longitudinal analysis of select influences on the development of occupational aspirations. Journal of Vocational Behavior, 51, 375410.

Sanford, C., Newman, L., Wagner, M., Cameto, R., Knokey, A. M., \& Shaver, D. (2011). The Post-High School Outcomes of Young Adults with Disabilities up to 6 Years after High School: Key Findings from the National Longitudinal Transition Study-2 (NLTS2). NCSER 2011-3004. National Center for Special Education Research.

Schoon, I. (2010). Planning for the future. Changing education expectations in three British cohorts. Historical Social Research, 35(2): 99-119

Schoon, I. (2008). A transgenerational model of status attainment: The potential mediating role of school motivation and education. National Institute Economic Review, 205, 72-82.

Schoon, I., \& Eccles, J. S. (Eds.). (2014). Gender differences in aspirations and attainment: A life course perspective. Cambridge University Press.

Schoon, I., Martin, P., \& Ross, A. (2007). Career transitions in times of social change. His and her story. Journal of Vocational Behavior, 70(1), 78-96.

Schoon, I., \& Parsons, S. (2002). Teenage aspirations for future careers and occupational outcomes. Journal of Vocational Behavior, 60(2), 262-288.

Schoon, I., \& Polek, E. (2011). Teenage career aspirations and adult career attainment: The role of gender, social background and general cognitive ability. International Journal of Behavioral Development, 35(3), 210-217. 
Skorikov, V. B., \& Vondracek, F. W. (2011). Occupational identity. In Handbook of identity theory and research (pp. 693-714). Springer New York.

Strand, S. (2007). Minority ethnic pupils in the Longitudinal Study of Young People in England (LSYPE). London: Department for children, schools and families (DCSF). Research Report No RR002.

Torgerson, C. J., Gorard, S., Low, G., Ainsworth, H. (2008). See, B. H. and Wright, K. (2008) What are the factors that promote high post-16 participation of many minority ethnic groups? A focused review of the UK-based aspirations literature in Research Evidence in Education Library. London: Evidence for Policy and Practice Information and Co-ordinating Centre (Social Science Research Unit, Institute of Education, University of London). Available at: http://eppi.ioe.ac.uk/cms/Default.aspx?tabid=2386 (accessed 28 November 2010).

Vondracek, F. W. (2001). The developmental perspective in vocational psychology. Journal of vocational behavior, 59(2), 252-261. 
Table 1

Career Aspirations of Young People According to SEN

\section{SEN Category}

\begin{tabular}{|c|c|c|c|c|}
\hline Career Aspirations & No SEN & SA & SAP & Statement \\
\hline Professional/Managerial & $30 \%{ }^{\mathrm{a}}$ & $19 \% 0^{\mathrm{b}}$ & $15 \%{ }^{c}$ & $15 \%{ }^{c}$ \\
\hline Skilled & $40 \%{ }^{\mathrm{a}}$ & $48 \%{ }^{b}$ & $50 \%$ b & $44 \% 0^{b}$ \\
\hline Unskilled & $10 \%{ }^{\mathrm{a}}$ & $13 \%{ }^{b}$ & $15 \%{ }^{b}$ & $11 \%{ }^{a, b}$ \\
\hline Uncertain & $20 \%{ }^{a}$ & $20 \%{ }^{a}$ & $20 \%{ }^{\mathrm{a}}$ & $30 \%{ }^{b}$ \\
\hline $\mathrm{N}$ & 8,449 & 988 & 384 & 145 \\
\hline
\end{tabular}

Note. SEN categories with the same subscript letter do not differ significantly from each other at the 05 level, while those SEN categories with different subscript letters differ significantly at the .05 level. 
Table 2

Differences among SEN provision for covariates and outcomes

Means(SD)

\begin{tabular}{|c|c|c|c|c|c|}
\hline Variables & No SEN & SA & SAP & Statement & \\
\hline Male & $.49(.50)^{\mathrm{a}}$ & $.59(.49)^{\mathrm{b}}$ & $.62(.49)^{\mathrm{c}}$ & $.81(.39)^{\mathrm{d}}$ & $38.77^{* * *}$ \\
\hline Ethnic Minority & $.32(.47)^{\mathrm{a}}$ & $.40(.49)^{\mathrm{b}}$ & $.35(.48)^{\mathrm{b}}$ & $.33(.47)^{\mathrm{a}}$ & $7.91^{* * *}$ \\
\hline Parent Occupation & $3.01(.93)^{\mathrm{a}}$ & $2.64(.96)^{\mathrm{b}}$ & $2.52(.96)^{\mathrm{b}}$ & $2.73(.90)^{\mathrm{b}}$ & $82.05^{* * *}$ \\
\hline Parent Education & $2.32(1.33)^{\mathrm{a}}$ & $1.89(1.19)^{\mathrm{b}}$ & $1.88(1.20)^{\mathrm{b}}$ & $1.85(1.17)^{\mathrm{b}}$ & $45.83^{* * *}$ \\
\hline Parents Marital Status & $.77(.42)^{\mathrm{a}}$ & $.63(.48)^{\mathrm{b}}$ & $.56(.50)^{\mathrm{b}, \mathrm{c}}$ & $.69(.47)^{\mathrm{a}, \mathrm{b}}$ & $60.15^{* * *}$ \\
\hline Prior Academic Ability & $.24(.83)^{\mathrm{a}}$ & $-.85(.95)^{\mathrm{b}}$ & $-.92(1.04)^{b}$ & $-1.67(1.00)^{c}$ & $867.11^{* * *}$ \\
\hline Parent Expectations & $.78(.42)^{\mathrm{a}}$ & $.57(.49)^{\mathrm{b}}$ & $.49(.50)^{\mathrm{b}, \mathrm{c}}$ & $.48(.50)^{\mathrm{c}}$ & $132.07^{* * *}$ \\
\hline School Motivation & $3.22(.47)^{\mathrm{a}}$ & $3.07(.56)^{\mathrm{b}}$ & $2.99(.57)^{c}$ & $3.01(.53)^{\mathrm{b}, \mathrm{c}}$ & $61.78^{* * *}$ \\
\hline Academic Self-Concept & $3.09(.40)^{\mathrm{a}}$ & $2.96(.43)^{b}$ & $2.89(.46)^{c}$ & $2.82(.53)^{c}$ & $74.07^{* * *}$ \\
\hline Academic Performance at 16 & $325.25(81.64)^{\mathrm{a}}$ & $222.75(103.22)^{b}$ & $177.43(114.90)^{\mathrm{c}}$ & $164.98(104.83)^{\mathrm{c}}$ & $874.74^{* * *}$ \\
\hline NEET (16-20 years) & $2.84(6.59)^{\mathrm{a}}$ & $6.41(9.91)^{b}$ & $8.06(11.38)^{c}$ & $7.99(10.97)^{c}$ & $143.81^{* * *}$ \\
\hline
\end{tabular}

Note. SEN categories with the same subscript letter do not differ significantly from each other at the .05 level, while those SEN categories with different subscript letters differ significantly at the .05 level. 
Table 3

Regression Models of Academic Performance at Age 16

\begin{tabular}{|c|c|c|c|}
\hline Variables & Model 1 & Model 2 & Model 3 \\
\hline Constant & $149.77(6.11)^{* * *}$ & $157.87(6.42)^{* * *}$ & $157.45(6.43)^{* * *}$ \\
\hline SA & $-27.69(2.25)^{* * *}$ & $-27.75(2.24)^{* * *}$ & $-24.00(4.81)^{* * *}$ \\
\hline SAP/Statement & $-51.66(3.02)^{* * *}$ & $-51.86(3.01)^{* * *}$ & $-29.32(7.21)^{* * *}$ \\
\hline Male & $-14.34(1.28)^{* * *}$ & $-16.22(1.33)^{* * *}$ & $-16.11(1.33)^{* * *}$ \\
\hline Ethnic Minority & $12.98(1.43)^{* * *}$ & $11.00(1.45)^{* * *}$ & $10.95(1.45)^{* * *}$ \\
\hline Skilled Parent Occupation & $-6.84(1.60)^{* * *}$ & $-6.60(1.60)^{* * *}$ & $-6.65(1.60)^{* * *}$ \\
\hline Unskilled Parent Occupation & $-19.07(1.76)^{* * *}$ & $-18.93(1.76)^{* * *}$ & $-18.94(1.76)^{* * *}$ \\
\hline Highest Parental Education & $5.15(.55)^{* * *}$ & $5.10(.55)^{* * *}$ & $5.08(.54)^{* * *}$ \\
\hline Parental Marital Status & $25.04(1.50)^{* * *}$ & $24.63(1.49)^{* * *}$ & $24.61(1.49)^{* * *}$ \\
\hline Prior Academic Ability & $51.02(.83)^{* * *}$ & $50.19(.83)^{* * *}$ & $50.18(.83)^{* * *}$ \\
\hline Parental Expectations & $25.91(1.59)^{* * *}$ & $24.55(1.60)^{* * *}$ & $24.52(1.60)^{* * *}$ \\
\hline School Motivation & $25.99(1.36)^{* * *}$ & $25.73(1.36)^{* * *}$ & $25.71(1.36)^{* * *}$ \\
\hline Academic Self-Concept & $12.65(1.70)^{* * *}$ & $12.44(1.70)^{* * *}$ & $12.36(1.70)^{* * *}$ \\
\hline Skilled Career Aspirations & & $-5.59(1.58)^{* * *}$ & $-4.29(1.66)^{* *}$ \\
\hline Unskilled Career Aspirations & & $-16.12(2.38)^{* * *}$ & $-13.67(2.57)^{* * *}$ \\
\hline Uncertain Career Aspirations & & $1.58(1.84)$ & $1.82(1.96)$ \\
\hline SA*Skilled & & & $-5.79(5.64)$ \\
\hline SA*Unskilled & & & $-11.82(7.52)$ \\
\hline SA*Uncertain & & & $1.88(6.65)$ \\
\hline SAP/Statement *Skilled & & & $-27.33(8.25)^{* * *}$ \\
\hline SAP/Statement *Unskilled & & & $-32.16(10.38)^{* *}$ \\
\hline SAP/Statement*Uncertain & & & $-22.46(9.35)^{*}$ \\
\hline$F$ & $1213.87^{* * *}$ & $981.59^{* * *}$ & $702.73^{* * *}$ \\
\hline$R^{2}$ & .60 & .60 & .61 \\
\hline
\end{tabular}

Note. ${ }^{* * *} \mathrm{p}<.001,{ }^{* *} \mathrm{p}<.01,{ }^{*} \mathrm{p}<.05$ 
Table 4

Regression Models of Months in NEET between ages 16 and 20

\begin{tabular}{|c|c|c|c|}
\hline Variables & Model 1 & Model 2 & Model 3 \\
\hline Constant & $9.15(.80)^{* * *}$ & $8.96(.84)^{* * *}$ & $9.03(.84)^{* * *}$ \\
\hline SA & $1.32(.29)^{* * *}$ & $1.32(.29)^{* * *}$ & $.72(.64)$ \\
\hline SAP/Statement & $2.18(.42)^{* * *}$ & $2.18(.42)^{* * *}$ & $.00(.91)$ \\
\hline Male & $-.04(.16)$ & $-.07(.17)$ & $-.08(.17)$ \\
\hline Ethnic Minority & $-.49(.19)^{* *}$ & $-.49(.19)^{* *}$ & $-.49(.19)^{* *}$ \\
\hline Skilled Parental Occupation & $-.09(.20)$ & $-.09(.20)$ & $-.08(.20)$ \\
\hline Unskilled Parental Occupation & $1.02(.22)^{* * *}$ & $1.02(.22)^{* * *}$ & $1.03(.22)^{* * *}$ \\
\hline Highest Parental Education & $-.12(.07)$ & $-.12(.07)$ & $-.12(.07)$ \\
\hline Parental Marital Status & $-1.36(.20)^{* * *}$ & $-1.36(.20)^{* * *}$ & $-1.36(.20)^{* * *}$ \\
\hline Prior Academic Ability & $-.99(.11)^{* * *}$ & $-.99(.11)^{* * *}$ & $-.98(.11)^{* * *}$ \\
\hline Parental Expectations & $-1.25(.21)^{* * *}$ & $-1.24(.21)^{* * *}$ & $-1.24(.21)^{* * *}$ \\
\hline School Motivation & $-1.11(.18)^{* * *}$ & $-1.11(.18)^{* * *}$ & $-1.10(.18)^{* * *}$ \\
\hline Academic Self-Concept & $-.09(.22)$ & $-.09(.22)$ & $-.09(.22)$ \\
\hline Skilled Career Aspirations & & $1.22(.20)$ & $.00(.20)$ \\
\hline Unskilled Career Aspirations & & $.03(.31)$ & $-.22(.33)$ \\
\hline Uncertain Career Aspirations & & $.22(.23)$ & $.12(.25)$ \\
\hline SA*Skilled & & & $.66(.75)$ \\
\hline SA*Unskilled & & & $1.57(1.00)$ \\
\hline SA*Uncertain & & & $.48(.88)$ \\
\hline SAP/Statement $*$ Skilled & & & $2.75(1.08)^{*}$ \\
\hline SAP/Statement *Unskilled & & & $2.97(1.41)^{*}$ \\
\hline SAP/Statement*Uncertain & & & $2.57(1.22)^{*}$ \\
\hline$F$ & $60.39^{* * *}$ & $48.37^{* * *}$ & $35.03^{* * *}$ \\
\hline$R^{2}$ & .09 & .09 & .10 \\
\hline
\end{tabular}

Note. ${ }^{* * *} \mathrm{p}<.001,{ }^{* *} \mathrm{p}<.01,{ }^{*} \mathrm{p}<.05$ 
Figure 1. Significant Interactions between SEN and Career Aspirations for Academic Performance at Age 16
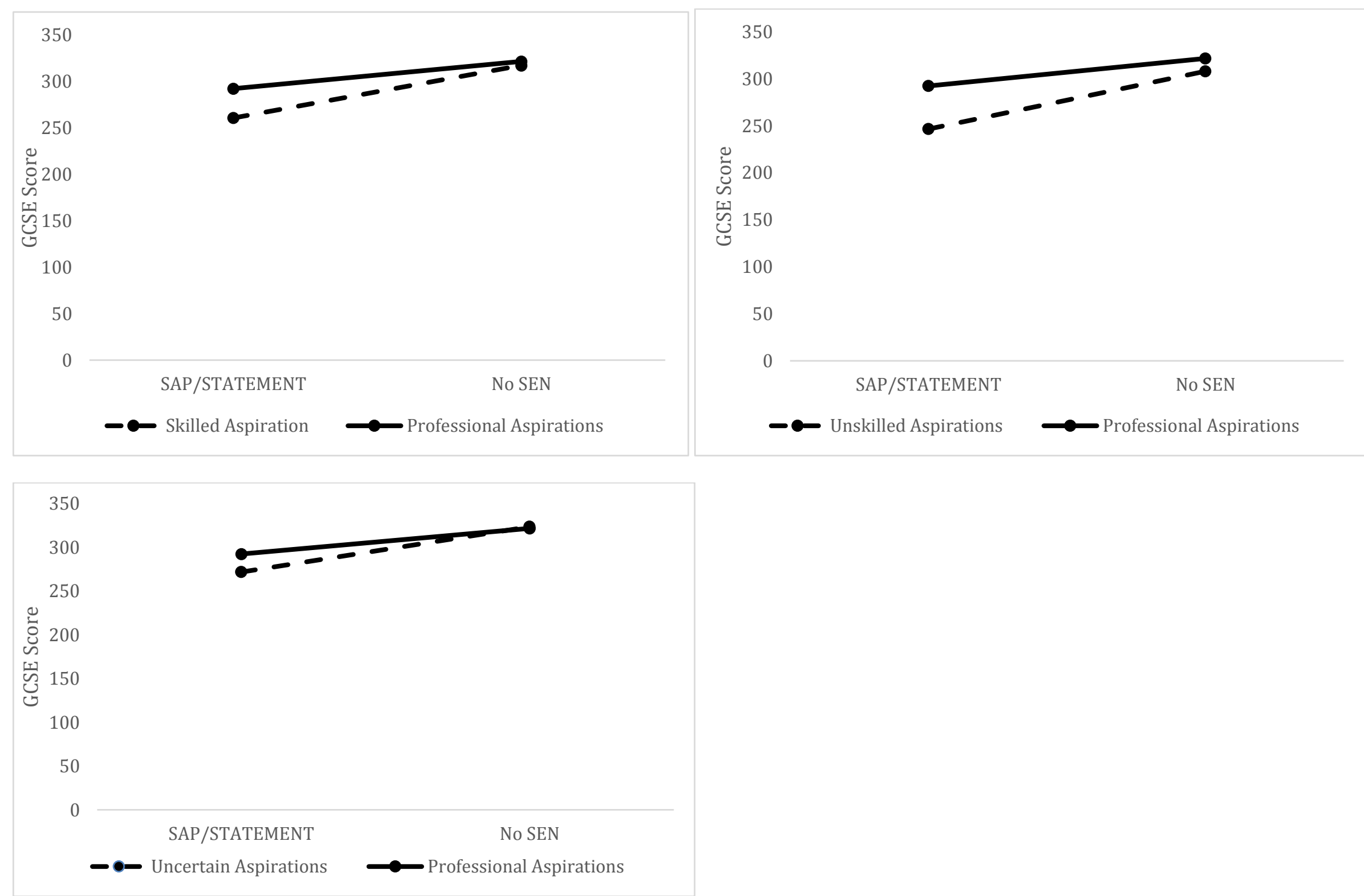
Figure 2. Significant Interactions between SEN and Career Aspirations for Months being NEET from Ages 16 to 20
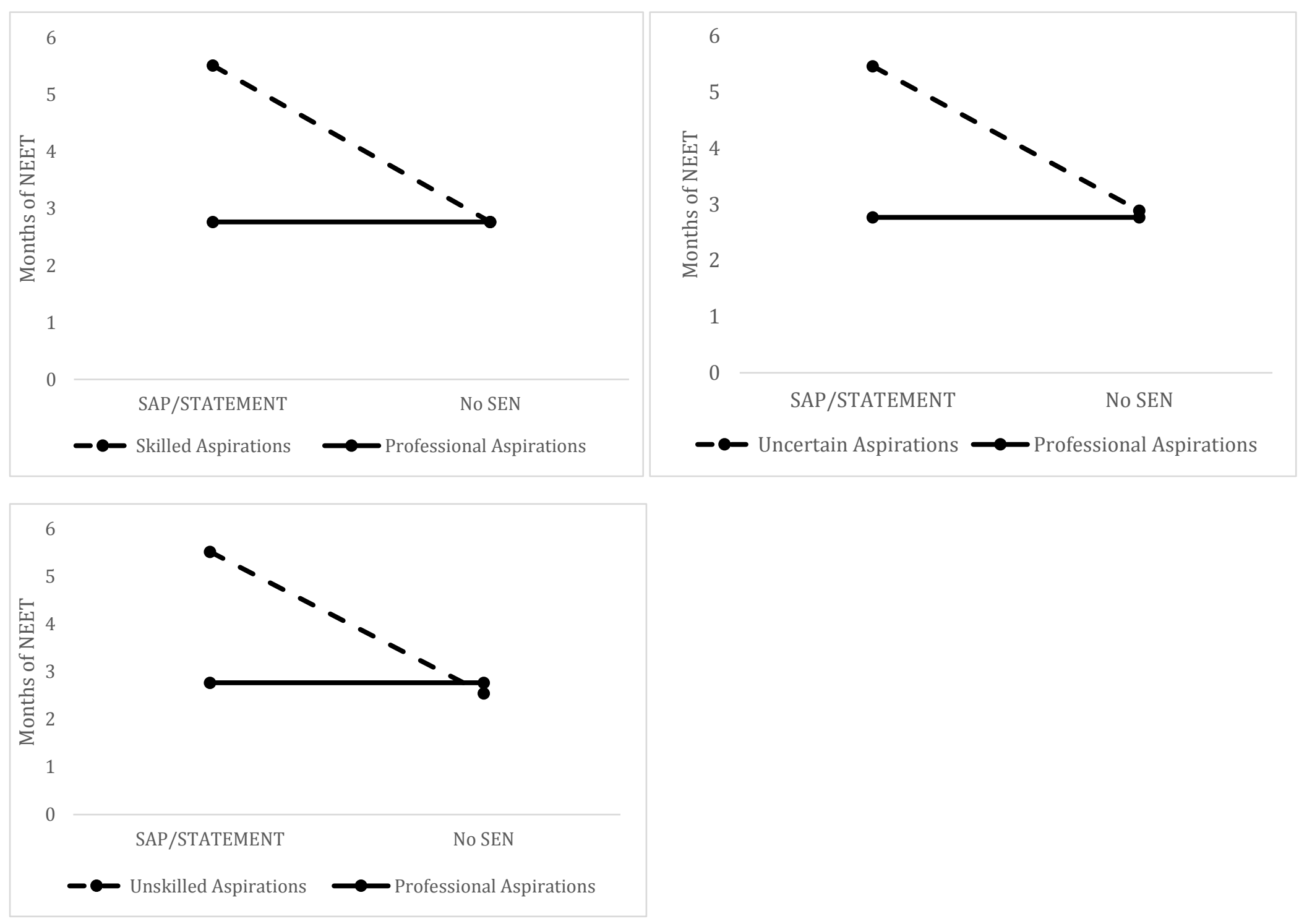
